\title{
Analysis of covalent ellipticine- and doxorubicin-derived adducts in DNA of neuroblastoma cells by the ${ }^{32} \mathrm{P}$-postlabeling technique
}

\author{
This work is dedicated to Professor Gustav Entlicher on the occasion of his $70^{\text {th }}$ birthday
}

\author{
Marie Stiborovaa ${ }^{a}$ Jitka Poljakova ${ }^{a}$, Tomas Eckschlager ${ }^{b}$, Rene Kizek, ${ }^{c, d}$ Eva Frei ${ }^{e}$
}

\begin{abstract}
Background. Ellipticine and doxorubicin are antineoplastic agents, whose action is based mainly on DNA damage such as intercalation, inhibition of topoisomerase II and formation of covalent DNA adducts. The key target to resolve which of these mechanisms are responsible for ellipticine and doxorubicin anticancer effects is the development of suitable methods for identifying their individual DNA-damaging effects. Here, the ${ }^{32} \mathrm{P}$-postlabeling method was tested to detect covalent DNA adducts formed by ellipticine and doxorubicin.

Methods. The standard procedure of ${ }^{32} \mathrm{P}$-postlabeling assay, this procedure under ATP-deficient conditions, the version using extraction of adducts with $n$-butanol and the nuclease P1 enrichment version were used to analyze ellipticineand/or doxorubicin-derived DNA adducts.

Results. Two covalent ellipticine-derived DNA adducts, which are associated with cytotoxicity of ellipticine to human UKF-NB-3 and UKF-NB-4 neuroblastoma cell lines, were detected by the ${ }^{32}$ P-postlabeling method. These adducts are identical to those formed by the ellipticine metabolites, 13-hydroxy- and 12-hydroxyellipticine. In contrast, no covalent adducts formed by doxorubicin in DNA of these neuroblastoma cells and in DNA incubated with this drug and formaldehyde in vitro were detectable by the ${ }^{32} \mathrm{P}$-postlabeling assay.

Conclusions. The results presented in this paper are the first to demonstrate that in contrast to covalent DNA adducts formed by ellipticine, the adducts generated by formaldehyde-mediated covalent binding of doxorubicin to DNA are not detectable by the ${ }^{32} \mathrm{P}$-postlabeling assay. No DNA adducts were, detectable either in vitro, in incubations of DNA with doxorubicin or in DNA of neuroblastoma cells treated with this drug. The results also suggest that covalent binding of ellipticine to DNA of UKF-NB-3 and UKF-NB-4 neuroblastoma cell lines is the predominant mechanism responsible for the cytotoxicity of this drug. To understand the mechanisms of doxorubicin anticancer effects on neuroblastoma cells, development of novel methods for identifying covalent doxorubicin-derived DNA adducts is the major challenge for further research.
\end{abstract}

Key words: ellipticine, doxorubicin, neuroblastoma, DNA adducts, ${ }^{32} \mathrm{P}$-postlabeling, cancer

Received: November 17, 2011; Accepted with revision: April 4, 2012; Available online: June 1, 2012 http://dx.doi.org/10.5507/bp.2012.043

aDepartment of Biochemistry, Faculty of Science, Charles University, Albertov 2030, 12840 Prague 2, Czech Republic ${ }^{b}$ Department of Pediatric Hematology and Oncology, $2^{\text {nd }}$ Medical School, Charles University and University Hospital Motol, V Uvalu 84, 15006 Prague 5

'Department of Chemistry and Biochemistry, Faculty of Agronomy, Mendel University in Brno, Zemedelska 1, 61300 Brno

${ }^{d}$ Central European Institute of Technology, Brno University of Technology, Technicka 3058/10, 61600 Brno

'Division of Preventive Oncology, National Center for Tumor Diseases, German Cancer Research Center (DKFZ), Im Neuenheimer Feld 280 , 69120 Heidelberg, Germany

Corresponding author: Marie Stibovova, e-mail: marie.stiborova@natur.cuni.cz

\section{INTRODUCTION}

Neuroblastoma, a tumor of the peripheral sympathetic nervous system, is the most frequent solid extracranial neurological tumor in children and is a major cause of death from neoplasia in infancy ${ }^{1,2}$. These tumors are biologically heterogeneous, with cell populations differing in their genetic programs, maturation stage and malignant potential $^{3}$. Neuroblastoma consists of three principal neoplastic cells $s^{4,5}:$ i) neuroblastic or N-type: undifferentiated, round and small cells with scant cytoplasm and neuritic processes; ii) stromal or S-type: large, flattened and adherent differentiated cells; and iii) intermediate or I-type with morphological features of both above mentioned types i.e. cells with short neurite-like processes such as adherent growth. As neuroblastoma cells seem to have the capacity to differentiate spontaneously in vivo and in vitro ${ }^{6}$, their heterogeneity could affect treatment outcome, in particular the response to apoptosis induced by chemotherapy. Neuroblastoma may regress spontaneously in infants, mature to benign ganglioneuromas, or grow relentlessly and be rapidly fatal ${ }^{3}$. The prognosis for patients with high 


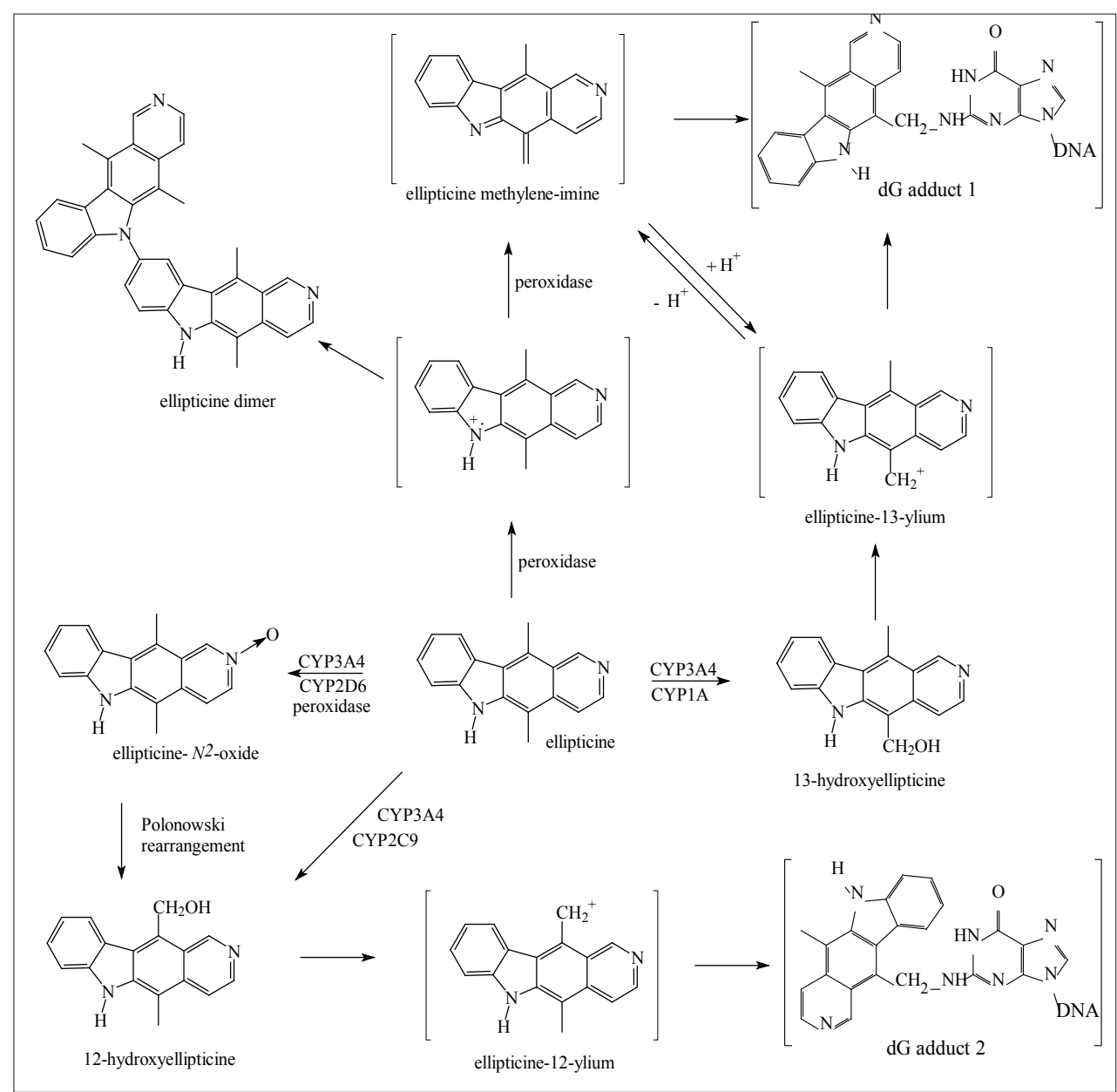

Fig. 1. Scheme of the metabolism of ellipticine by human CYPs and peroxidases showing the characterized detoxication metabolites and those proposed to form DNA adducts. The compounds shown in brackets are the hypothetical electrophilic metabolites postulated as ultimate arylating species or the postulated $N^{2}$-deoxyguanosine adducts. risk tumors is poor, in spite of intensive therapy including megatherapy with subsequent hematopoietic progenitor cell transplantation, biotherapy and immunotherapy because drug resistance arises in the majority of these patients who initially responded to chemotherapy ${ }^{3}$.

Chemotherapy agents used in combination have been found to be effective against neuroblastoma. Agents commonly used are platinum compounds (carboplatin), alkylating agents (cyclophosphamide, ifosfamide, melphalan), topoisomerase II inhibitors (etoposide), anthracycline antibiotics (doxorubicin) and vinca alkaloids (vincristine). Some novel regimens include also topoisomerase I inhibitors (topotecan and irinotecan), which have been found to be effective against recurrent disease ${ }^{3}$. Nevertheless, little improvement in therapeutic options has been made in the last decade, requiring a need for the development of new therapies.

Recently, we have suggested novel treatment of neuroblastomas, utilizing a drug targeting DNA, the plant alkaloid ellipticine (5,11-dimethyl-6H-pyrido[4,3-b]carbazole, Fig.1). We found that exposure of human neuroblastoma IMR-32, UKF-NB-3 and UKF-NB-4 cell lines to this agent resulted in strong inhibition of cell growth, followed by induction of apoptosis ${ }^{7}$. These effects were associated with formation of two covalent ellipticine-derived DNA adducts, identical to those formed by the cytochrome P450 (CYP)- and peroxidase-mediated ellipticine metabolites, 13-hydroxy- and 12-hydroxyellipticine (Fig. 1). In addition, other mechanisms, such as intercalation into DNA $\left(\right.$ ref. $^{8}$ ), and inhibition of DNA topoisomerase II activity ${ }^{8-11}$ resulting in ellipticine toxicity to neuroblastoma cannot be excluded (for a summary see ${ }^{12-15}$ ).

Of anthracycline antibiotics, doxorubicin (Fig. 2A) is frequently used for neuroblastoma treatment ${ }^{3}$. The primary mechanism of action of doxorubicin (and other anthracyclines) appears to be poisoning of the enzyme topoisomerase II which results in double-strand DNA breaks, and the failure to repair these breaks leads to apoptosis $^{15,16}$. More recently however, it has been demonstrated that doxorubicin also forms covalent adducts with DNA and these lesions are more cytotoxic than those induced by topoisomerase II impairment ${ }^{17}$. The adducts are formed predominantly at 50-GC-30 sites in DNA (ref. ${ }^{18}$ ), where the doxorubicin sugar group (daunosamine) is covalently linked to the $\mathrm{N}-2$ amino group of guanine via an aminal (N-C-N) bond ${ }^{19-22}$. The central carbon atom in the aminal bond is derived from formaldehyde, hence formaldehyde is an absolute requirement for adduct formation $^{20,21}$. This compound is present in cancer cells, at levels which are often even higher in tumor cells (1.5-4.0 $\mathrm{mM}$ ) than normal cells $\mathrm{s}^{23,24}$. Moreover, formaldehyde is also produced in cancer cells treated with doxorubicin, from the oxidation of doxorubicin itself ${ }^{20}$. The resulting drug-DNA monoadduct is further stabilized through in- 

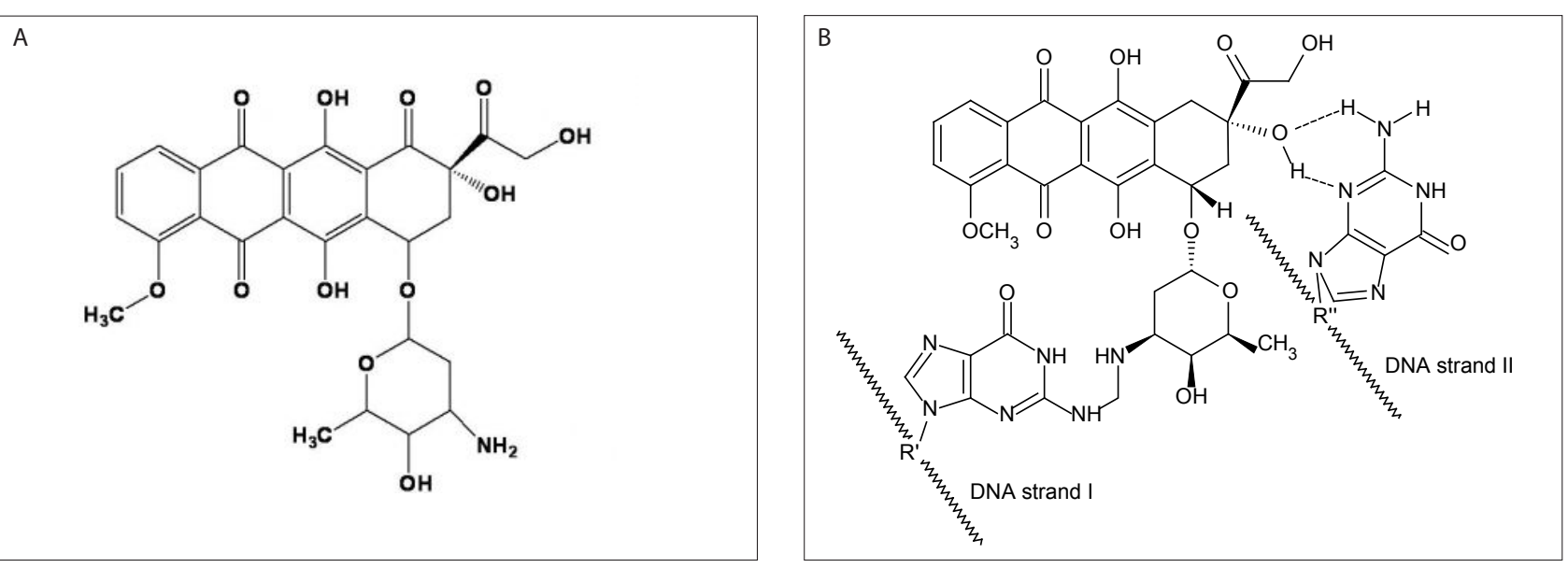

Fig. 2. Structures of doxorubicin (A) and doxorubicin-DNA adduct (B) (adapted from ${ }^{27}$ ).

tercalation and hydrogen bonding with the second strand of DNA (ref. ${ }^{21}$ ) (Fig. 2B).

Even though ellipticine and doxorubicin are cytotoxic to neuroblastomas ${ }^{7}$, the question arises whether the covalent DNA adduct formation is the predominant mechanism responsible for this cytotoxic effect. To answer this question, development of methods suitable for detecting and quantifying covalent DNA adducts formed by ellipticine and doxorubicin is the first and key target of the research. Using ${ }^{14} \mathrm{C}$-labeled doxorubicin, doxorubicinDNA adduct formation has been detected in several cancer cells ${ }^{17,20,21,25}$. Moreover, accelerator mass spectrometry has recently also been shown suitable for detecting the covalent ${ }^{14} \mathrm{C}$-labeled doxorubicin-DNA adducts in cancer cells exposed to this drug ${ }^{26-28}$. Utilizing the ${ }^{14} \mathrm{C}$-labeled doxorubicin has, however, limitations for use in human treatment.

${ }^{32} \mathrm{P}$-postlabeling is the commonest method for determination of DNA adducts formed by several substances that covalently modify DNA ( ref. $^{29-32}$ ). However, whereas it is useful for detecting and quantifying covalent ellipticinederived DNA adducts ${ }^{12,14,15,33,34}$, its ability to determine covalent doxorubicin-DNA adducts remains to be resolved. The present study was therefore undertaken to investigate whether covalent doxorubicin-DNA adducts are detectable by the ${ }^{32} \mathrm{P}$-postlabeling technique. DNA adducts formed by doxorubicin in DNA of neuroblastoma cells and in DNA incubated with this drug and formaldehyde were analyzed. Since neuroblastoma is heterogenous and this feature could affect its treatment, two types of neuroblastoma cell lines were tested for their response to treatment by ellipticine and doxorubicin, UKF-NB-3 cells (the invasive N-type), and UKF-NB-4 cells (the less-aggressive S-type). DNA from UKF-NB-3 and UKF-NB-4 cell lines treated with ellipticine and doxorubicin in concentrations that are toxic to these cells was isolated and formation of covalent DNA adducts by ellipticine and doxorubicin analyzed.

\section{MATERIAL AND METHODS}

\section{Chemical}

Ellipticine was obtained from Sigma (St. Louis, MO, USA). Doxorubicin was obtained from EBEWE Pharma Ges.m.b.H. (Unterach, Austria), dimethyl sulfoxide (DMSO) from Amresco Inc. (Solon, OH, USA), phenolchloroform from Roth (Karlsruhe, Germany) and isopropanol from PLIVA-Lachema (Brno, Czech Republic). 12-Hydroxy- and 13-hydroxyellipticine were isolated from multiple high-performance liquid chromatography (HPLC) runs of ethyl acetate extracts of incubations containing ellipticine and human and/or rat hepatic microsomes as described ${ }^{12,33,34}$. All these and other chemicals used in the experiments were of analytical purity or better. Enzymes and chemicals for the ${ }^{32} \mathrm{P}$-postlabeling assay were obtained from sources described ${ }^{12}$. All other chemicals used in the experiments were of analytical purity or better.

\section{Synthesis of covalent formaldehyde-mediated doxorubicin-DNA adducts}

Multiple 0.5-ml reactions were run in parallel according the procedure described by Zeman et al. ${ }^{21}$. Briefly, each reaction mixture contained $125 \mathrm{mM}$ calf thymus DNA, $125 \mathrm{mM}$ doxorubicin, and $0.37 \%$ formaldehyde in $20 \mathrm{mM}$ sodium phosphate buffer ( $\mathrm{pH}$ 7.0) containing $150 \mathrm{mM} \mathrm{NaCl}$ and $0.5 \mathrm{mM}$ EDTA. Reactions were run at $10{ }^{\circ} \mathrm{C}$ for $4 \mathrm{~h}$, the time determined for nearly $100 \%$ conversion of all DNA to covalent species ${ }^{21}$. DNA was isolated from the mixture by its precipitation with 2.5 times the volume of ethanol $\left(-20{ }^{\circ} \mathrm{C}\right)$, washed twice with $5 \mathrm{ml}$ of $70 \%$ ethanol, $5 \mathrm{ml}$ of absolute ethanol and $5 \mathrm{ml}$ of diethyl ether. DNA was dried under a stream of nitrogen and dissolved in distilled water.

\section{Cell cultures}

The UKF-NB-3 and UKF-NB-4 neuroblastoma cell lines, established from bone marrow metastases of high risk neuroblastoma, were a gift of Prof. J. Cinatl, Jr. (J. W. Goethe University, Frankfurt, Germany). UKF-NB-4 was derived from recurrent disease. Both cell lines used were derived from high risk neuroblastoma with MYCN am- 


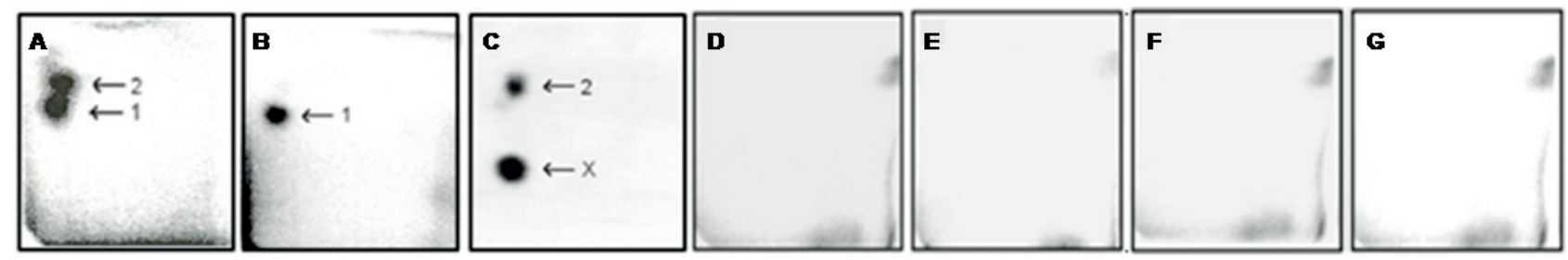

Fig. 3. Autoradiographs of PEI-cellulose TLC maps of ${ }^{32} \mathrm{P}-$-labeled digests of DNA isolated from neuroblastoma UKF-NB-3 exposed to $10 \mu \mathrm{M}$ ellipticine for $48 \mathrm{~h}$ (A) ( ref. $^{7}$ ), from calf thymus DNA reacted with 13-hydroxyellipticine (B) and 12-hydroxyellipticine (C) (ref. ${ }^{33,34}$ ). Analyses were performed by the nuclease P1 version of the ${ }^{32}$ P-postlabeling assay. (D-G) Autoradiographs of PEI-cellulose TLC maps of of ${ }^{32} \mathrm{P}$-labeled digests of DNA isolated from neuroblastoma UKF-NB-3 exposed to $10 \mu \mathrm{M}$ doxorubicin for $48 \mathrm{~h}$. The standard procedure of the ${ }^{32} \mathrm{P}$-postlabeling assay was used for the TLC map in panel (D), the standard procedure under ATP-deficient conditions for that in panel (E), the nuclease P1 version for that in panel (F) and the version utilizing extraction of adducts into $n$-butanol for that in panel (G). The method A (see the Material and methods section) was utilized for resolution of adducts in all panels. (A) Scans of the plates from the imager for $6.5 \mathrm{~min}$; (B,C) autoradiographs of films exposed for $1 \mathrm{~h}$ at -80 ${ }^{\circ} \mathrm{C}$; (D-G) scans of the plates from the imager for $1 \mathrm{~h}$. Origins are located at the bottom left corners (D3 from bottom to top and D4 from left to right).

plification, dellp and aneuploidy. Cells were grown at $37{ }^{\circ} \mathrm{C}$ and $5 \% \mathrm{CO}_{2}$ in Iscove's modified Dulbecco's medium (IMDM) (Lonza Inc, Allendale, NJ, USA), supplemented with $10 \%$ fetal calf serum, $2 \mathrm{mM}$ L-glutamine, 100 units/ml of penicilline and $100 \mu \mathrm{g} / \mathrm{ml}$ streptomycine (PAA Laboratories, Pasching, Austria). For hypoxia experiments, cells were maintained in modular incubator chamber (Billups-Rothenberg Inc., Del Mar, CA, USA) flushed with $1 \% \mathrm{O}_{2}, 5 \% \mathrm{CO}_{2}$ and balance $\mathrm{N}_{2}$ for $4 \mathrm{~min}$ (hereafter referred to as hypoxia). This chamber was placed into $37^{\circ} \mathrm{C}$.

\section{Treatment of neuroblastoma cells with ellipticine and doxorubicin for DNA adduct analyses}

Neuroblastoma cell lines were seeded $24 \mathrm{~h}$ prior to treatment at a density of $5 \times 10^{5}$ cells $/ \mathrm{ml}$ in two $75 \mathrm{~cm}^{2} \mathrm{cul}-$ ture flasks in a total volume of $20 \mathrm{ml}$ of IMDM. Ellipticine and doxorubicin were dissolved in $5 \mu \mathrm{l}$ of DMSO and distilled water, respectively. The final concentration was 1 or $10 \mu \mathrm{M}$. After $48 \mathrm{~h}$ the cells were harvested after trypsinizing by centrifugation at $2000 \mathrm{x}$ g for $3 \mathrm{~min}$ and two washing steps with $5 \mathrm{ml}$ of PBS yielded a cell pellet, which was stored at $-80{ }^{\circ} \mathrm{C}$ until DNA isolation. DNA was isolated and labeled as described in the next section.

\section{DNA isolation}

DNA from cells treated with ellipticine and doxorubicin was isolated by the phenol-chloroform extraction as described ${ }^{7}$.

\section{${ }^{32}$ P-postlabeling of ellipticine-derived DNA adducts}

The ${ }^{32} \mathrm{P}$-postlabeling of nucleotides using nuclease P1 enrichment procedure ${ }^{31}$, found previously to be appropriate to detect and quantify ellipticine-derived DNA adducts formed in vitro and in vivo ${ }^{12,14,33,34}$ was used previously to detect and quantify the adducts formed in neuroblastoma cells ${ }^{7}$. DNA isolated from neuroblastoma cells as described in that study ${ }^{7}$ and DNA from experiments performed earlier, namely, calf thymus DNA incubated with 13-hydroxy- and 12-hydroxyellipticine ${ }^{33,34}$ were labeled with ${ }^{32} \mathrm{P}$ to show and compare adduct spot patterns.

\section{${ }^{32} \mathrm{P}$-postlabeling of doxorubicin-derived DNA adducts}

The standard procedure ${ }^{29}$, this procedure under the ATP-deficient conditions ${ }^{30}$, the version using extraction of adducts with $n$-butanol ${ }^{35}$ and the nuclease P1 enrichment version ${ }^{31}$ of the ${ }^{32} \mathrm{P}$-postlabeling assay were used. Labeled DNA digests were separated by two chromatographic methods on polyethylenimine (PEI)-cellulose plates. (i) Essentially as described ${ }^{29}$, except that D3 solvent was 3.5 $\mathrm{M}$ lithium formate, $8.5 \mathrm{M}$ urea ( $\mathrm{pH} 3.5)$; D4 solvent was $0.8 \mathrm{M}$ lithium chloride, 0.5 M Tris, 8.5 M urea ( $\mathrm{pH} 8.0$ ), followed by a final wash with $1.7 \mathrm{M}$ sodium phosphate (pH 6.0). D2 was omitted (method A). (ii) ${ }^{32}$ P-labeled adducts were also resolved by a modification described by Reddy et $\mathrm{al}^{32}$. This procedure has been shown to be suitable for resolution of DNA adducts formed by $o$ anisidine $^{36}$ or $o$-nitroanisole ${ }^{37}$. The solvents used in this case were: D1, 2.3 M sodium phosphate ( $\mathrm{pH}$ 5.77); D2 was omitted; D3, $2.7 \mathrm{M}$ lithium formate, 5.1 M urea $(\mathrm{pH}$ 3.5); D4, $0.36 \mathrm{M}$ sodium phosphate, $0.23 \mathrm{M}$ Tris- $\mathrm{HCl}$, 3.8 M urea ( $\mathrm{pH} 8.0)$. After D4 development and brief water wash, the sheets were developed (along D4) in 1.7 M sodium phosphate ( $\mathrm{pH} \mathrm{6.0)} \mathrm{(D5),} \mathrm{to} \mathrm{the} \mathrm{top} \mathrm{of} \mathrm{the}$ plate, followed by an additional 30-40 min development with the TLC tank partially opened, to allow the radioactive impurities to concentrate in a band close to the top edge (method B) $\left(\right.$ ref. $\left.^{32,36,37}\right)$. Adduct levels were calculated in units of relative adduct labeling (RAL), which is the ratio of c.p.m. of adducted nucleotides to c.p.m. of total nucleotides in the assay.

\section{RESULTS AND DISCUSSION}

\section{DNA adduct formation by ellipticine and doxorubicin analyzed with ${ }^{32}$ P-postlabeling}

As shown in our previous study ${ }^{7}$, ellipticine and doxorubicin are cytotoxic to human UKF-NB-3 and UKNNB-4 neuroblastoma cells. The toxicity of ellipticine and doxorubicin to both neuroblastoma cell lines was similar; $\mathrm{IC}_{50}$ values ranged from 0.42 to $0.70 \mu \mathrm{M}$ (ref. ${ }^{7}$ ). It should be noted, however, that even though the $\mathrm{IC}_{50}$ values for 
ellipticine for both neuroblastoma cell lines did not differ significantly, the UKF-NB-4 cell line (the less-aggressive S-type line) was less sensitive to this drug than the UKFNB-3 cell line. No viability of a UKF-NB-3 neuroblastoma cell line was found at $0.75 \mu \mathrm{M}$ ellipticine in cultivation medium, while viability of UKF-NB-4 cells was found up to ellipticine concentrations of $6.3 \mu \mathrm{M}$.

DNA adducts were analyzed in DNA of neuroblastoma cells treated with 1 and $10 \mu \mathrm{M}$ ellipticine and doxorubicin, the concentrations that are toxic to these cells. Formation of ellipticine-derived DNA adducts in UKF-NB-3 and UKN-NB-4 neuroblastoma cells has already been found in our previous work ${ }^{7}$. Therefore, their analysis in human UKF-NB-3 cells was used in the present study as positive control. As shown in Fig. 3A, two major ellipticine-derived DNA adducts formed in these neuroblastoma cells are generated from ellipticine-13-ylium and ellipticine-12-ylium (Fig. 1), the reactive species formed by dissociation of ellipticine metabolites, 13-hydroxy- and 12-hydroxyellipticine ${ }^{33,34}$ (Fig. 3B,C). Since ellipticine-derived DNA adducts have already been detected and quantitated using the nuclease P1 version of ${ }^{32} \mathrm{P}$-postlabeling assay ${ }^{12,33,34}$, this version of the method was first used also for analysis of DNA isolated from neuroblastoma cells treated with doxorubicin.

In contrast to these results, no adducts were found in DNA of cells treated with doxorubicin analyzed with the same version of the ${ }^{32}$ P-postlabeling method (Fig. 3F). Because the nuclease P1 version of the ${ }^{32} \mathrm{P}$-postlabeling method might have limitations for detecting some of DNA adducts ${ }^{35}$, we also used other versions of the ${ }^{32} \mathrm{P}$-postlabeling method such as the standard procedure ${ }^{28}$, this procedure under the ATP-deficient conditions ${ }^{30}$ and the version utilizing of extraction of adducts into $n$ butanol $^{35}$ to analyze doxorubicin-derived DNA adducts (Fig. 3D-G). Likewise, modifications of all versions that are appropriate for resolution of more polar adducts on thin layer of PEI cellulose such as the adducts generated in DNA by $o$-anisidine ${ }^{36}$ or $o$-nitroanisole ${ }^{37}$ (see method $\mathrm{B}$ in Material and Methods), were tested to determine doxorubicin-derived DNA adducts. Using all these methods, no adducts were again detected (data not shown). These findings might indicate at least two phenomena. First, low levels of covalent adducts (if any) that are undetectable by the ${ }^{32} \mathrm{P}$-postlabeling methods might be formed by doxorubicin in DNA of neuroblastoma cells. Their formation in neuroblastoma cells cannot, however, be excluded. Recently, changes in structure of DNA isolated from neuroblastoma cells induced by their treating with doxorubicin have been detected by square-wave voltammetry ${ }^{38}$. Nevertheless, whether these changes are produced by formation of actual covalent doxorubicinderived DNA adducts remain to be investigated. Second, the ${ }^{32} \mathrm{P}$-postlabeling method is not suitable to determine covalent adducts formed in DNA by doxorubicin.

In order to resolve whether the ${ }^{32} \mathrm{P}$-postlabeling method is suitable for detection of covalent formaldehydemediated doxorubicin-DNA adduct, we prepared the DNA adduct synthetically, by incubation of DNA with doxorubicin in the presence of formaldehyde, the compound necessary to covalent doxorubicin-DNA adduct formation $^{21}$. DNA incubated with doxorubicin and formaldehyde was isolated from the incubation mixture (see Material and Methods) and analyzed with all versions of the ${ }^{32} \mathrm{P}$-postlabeling method and two modifications used for resolution of adducts on PEI-cellulose TLC (see Materials and Methods). No DNA adducts were again detected (data not shown). These results indicate that none of the versions of the ${ }^{32} \mathrm{P}$-poslabeling assay is suitable for detecting formaldehyde-mediated covalent doxorubicin-DNA adducts. We can only speculate why formaldehyde-mediated covalent doxorubicin-DNA adduct is not detectable by ${ }^{32} \mathrm{P}$-postlabeling. One of the reasons for this finding, could be inefficient labeling reaction for formaldehyde-mediated doxorubicin-derived adduct during the ${ }^{32} \mathrm{P}$-postlabeling method, which is the conversion of the adducted nucleoside 3'-phosphate to its corresponding 3',5'-bisphosphate by T4 polynucleotide kinase. Further reasons could be incomplete digestion of modified DNA, loss of material during the experimental manipulations used in ${ }^{32} \mathrm{P}$-postlabeling or retaining compounds at the origin of the PEI-cellulose TLC plates. However, investigation of these features was beyond the scope of the present study.

\section{Cytotoxicity of and DNA adduct formation by ellipticine and doxorubicin in neuroblastoma cells cultivated under hypoxic conditions}

Hypoxia frequently occurs in tumors because of their fast growth and inadequate vascularisation. This strongly correlates with advanced disease and poor outcome caused by chemoresistance. As reported ${ }^{7}$, growth inhibition is mediated by ellipticine and doxorubicin in neuroblastoma cells even under hypoxic conditions of cultivation. Nevertheless, whereas a low effect of hypoxia was found on toxicity of both tested compounds to a UKFNB-3 cell line, the UKF-NB-4 neuroblastoma cells were less sensitive to both studied cytostatics under the hypoxic conditions of their cultivation?

Under hypoxic conditions, the ellipticine-DNA adduct levels in neuroblastoma cells were lower ${ }^{7}$, whereas formation of DNA adducts generated by doxorubicin in these cells was again not detectable. In both neuroblastoma cell lines treated with $10 \mu \mathrm{M}$ ellipticine, almost 2-fold decrease in levels of ellipticine-DNA adducts by hypoxia was found and resulted from a decreased formation of adducts 1 and 2 in both types of cells ${ }^{7}$. This finding shows that CYP enzymes, whose activities are dependent on oxygen $^{13,14,33,34}$, are predominantly responsible for formation of adducts 1 and 2 in these neuroblastoma cells ${ }^{7}$.

A decrease in the levels of adducts 1 and 2 in neuroblastoma cells under hypoxic conditions corresponded to a decrease in toxicity of ellipticine under these conditions $^{7}$. We therefore concluded that formation of ellipticine-DNA adducts was the predominant DNA-damaging mechanism of ellipticine action, resulting in its strong cytotoxicity to neuroblastoma cells. 


\section{CONCLUSIONS}

The results presented here are the first to demonstrate that in contrast to covalent DNA adducts formed by ellipticine, the adducts generated by formaldehyde-mediated covalent binding of doxorubicin to DNA are not detectable by the ${ }^{32} \mathrm{P}$-postlabeling assay. No DNA adducts were detectable in either in vitro, in incubations of DNA with doxorubicin or in DNA of neuroblastoma cells treated with this drug. The results of this and our previous study ${ }^{7}$ also suggest that covalent binding of ellipticine in DNA of UKF-NB-3 and UKF-NB-4 neuroblastoma cell lines is the predominant mechanism responsible for cytotoxicity of this drug to these cells. The mechanism of toxicity of doxorubicin to neuroblastoma cells has, however, not been resolved by this study and the development of novel methods identifying covalent doxorubicin-derived DNA adducts is the major challenge for further research.

\section{ABBREVIATIONS}

CYP, cytochrome P450; DMSO, dimethyl sulfoxide; IMDM, Iscove's modified Dulbecco's medium; HPLC, high-performance liquid chromatography; PBS, phosphate buffered saline; PEI-cellulose, polyethylenimine-cellulose; RAL, relative adduct labeling; SDS, sodium dodecyl sulphate; TLC, thin layer chromatography.

\section{ACKNOWLEDGEMENT}

We thank Prof. J .Cinatl, Jr. (J. W. Goethe University, Frankfurt, Germany) for providing cell lines. The work is supported by the Grant Agency of the Czech Republic (grant P301/10/0356) and CEITEC CZ.1.05/1.1.00/02.0068.

\section{REFERENCES}

1. Maris JM, Mathay KK Molecular biology of neuroblastomas. J Clin Oncol 1999;17:2264-79.

2. Schwab M. Human neuroblastoma: from basic science to clinical debut of cellular oncogenes. Naturwissenschaften 1999;86:71-8.

3. Brodeur GM. Neuroblastoma: biological insights into a clinical enigma. Nat Rev Cancer 2003;3:203-16.

4. Voigt A, Hartmann P, Zintl F. Differentiation, proliferation and adhesion of human neuroblastoma cells after treatment with retinoic acid. Cell Adhes Commun 2000;7:423-40.

5. Hopkins-Donaldson S, Yan P, Bourloud KB, Muhlethaler A, Bodmer $\mathrm{J}$, Gross N. Doxorubicin-induced death in neuroblastoma does not involve death receptors in S-type cells and is caspase-independent in N-type cells. Oncogene 2002;21:6132-7.

6. Morgenstern BZ, Krivoshik AP, Rodriguez V, Anderson PM. Wilms tumor and neuroblastoma. Acta Paediatr Suppl 2004;93:78-85.

7. Poljakova J, Eckschlager T, Hrabeta J, Hrebackova J, Smutny S, Frei E, Martínek V, Kizek R, Stiborová M. The mechanism of cytotoxicity and DNA adduct formation by the anticancer drug ellipticine in human neuroblastoma cells. Biochem Pharmacol 2009;77:1466-79.

8. Auclair C. Multimodal action of antitumor agents on DNA: The ellipticine series. Arch Biochem Biophys 1987;259:1-14.

9. Monnot M, Mauffret O, Simon V, Lescot E, Psaume B, Saucier JM, Charra M, Belehradek J Jr, Fermandjian S. DNA-drug recognition and effects on topoisomerase II-mediated cytotoxicity. A three-mode binding model for ellipticine derivatives. J Biol Chem 1991;25:18209.

10. Fossé P, Rene B, Charra M, Paoletti C, Saucier JM. Stimulation of topoisomerase II-mediated DNA cleavage by ellipticine derivatives: structure-activity relationships. Mol Pharmacol 1992;42:590-5.

11. Froelich-Ammon SJ, Patchan MW, Osheroff N, Thompson RB. Topoisomerase II binds to ellipticine in the absence or presence of DNA. Characterization of enzyme-drug interactions by fluorescence spectroscopy. J Biol Chem 1995;270:14998-15004.

12. Stiborová M, Bieler CA, Wiessler M, Frei E. The anticancer agent ellipticine on activation by cytochrome P450 forms covalent DNA adducts. Biochem Pharmacol 2001;62:1675-84.

13. Stiborová $M$, Rupertová $M$, Schmeiser HH, Frei E. Molecular mechanism of antineoplastic action of an anticancer drug ellipticine. Biomed Pap Med Fac Univ Palacky Olomouc Czech Repub 2006;150:13-23.

14. Stiborová M, Rupertová M, Frei E. Cytochrome P450- and peroxidasemediated oxidation of anticancer alkaloid ellipticine dictates its antitumor efficiency. Biochim Biophys Acta 2011;1814:175-85.

15. Kizek R, Adam V, Hrabeta J, Eckschlager T, Smutny S, Burda JV, Frei E, Stiborová M. Anthracyclines and ellipticines as DNA-damaging anticancer drugs; recent advances. Pharmacol Ther 2012;133:26-39.

16. Tewey KM, Rowe TC, Yang L, Halligan BD, Liu LF. Adriamycin-induced DNA damage mediated by mammalian DNA topoisomerase II. Science 1984;226:466-8.

17. Swift LP, Rephaeli A, Nudelman A, Phillips DR, Cutts SM. DoxorubicinDNA adducts induce a non-topoisomerase II-mediated form of cell death. Cancer Res 2006;66:4863-71.

18. Cullinane $C$, Phillips DR. Induction of stable transcriptional blockage sites by adriamycin: $\mathrm{GpC}$ specificity of apparent adriamycin-DNA adducts and dependence on iron(III) ions. Biochemistry 1990;29:563846.

19. Wang AH, Gao YG, Liaw YC, Li YK. Formaldehyde cross-links daunorubicin and DNA efficiently: HPLC and X-ray diffraction studies. Biochemistry 1991;30:3812-5.

20. Taatjes DJ, Gaudiano G, Resing K, Koch TH. Alkylation of DNA by the anthracycline, antitumor drugs adriamycin and daunomycin. J Med Chem 1996;39:4135-8.

21. Zeman SM, Phillips DR, Crothers DM. Characterization of covalent adriamycin-DNA adducts. Proc Natl Acad Sci USA 1998;95:11561-5.

22. Cutts SM, Parker BS, Swift LP, Kimura KI, Phillips DR. Structural requirements 2000;15:373-86.

23. Kato S, Burke PJ, Fenick DJ, Taatjes DJ, Bierbaum VM, Koch TH. Mass spectrometric measurement of formaldehyde generated in breast cancer cells upon treatment with anthracycline antitumor drugs. Chem Res Toxicol 2000;13:509-16.

24. Kato S, Burke PJ, Koch TH, Bierbaum VM. Formaldehyde in human cancer cells: detection by preconcentration-chemical ionization mass spectrometry. Anal Chem 2001;73:2992-7.

25. Coldwell KE, Cutts SM, Ognibene TJ, Henderson PT, Phillips DR. Detection of adriamycin-DNA adducts by accelerator mass spectrometry at clinically relevant adriamycin concentrations. Nucleic Acids Res 2008;36:e100.

26. Cutts SM, Rephaeli A, Nudelman A, Hmelnitsky I, Phillips DR. Molecular basis for the synergistic interaction of adriamycin with the formaldehyde-releasing prodrug pivaloyloxymethyl butyrate (AN-9). Cancer Res 2001;61:8194-202.

27. Cutts SM, Nudelman A, Rephaeli A, Phillips DR. The power and potential of doxorubicin-DNA adducts. Life. 2005;57:73-81.

28. Cutts SM, Swift LP, Pillay V, Forrest RA, Nudelman A, Rephaeli A, et al. Activation of clinically used anthracyclines by the formaldehyde-releasing prodrug pivaloyloxymethyl butyrate. Mol Cancer Ther 2007;6:1450-9.

29. Gupta RC, Reddy MV, Randerath K. ${ }^{32}$ P-postlabeling analysis of nonradioactive aromatic carcinogen--DNA adducts. Carcinogenesis 1982;3:1081-92.

30. Randerath E, Agrawal HP, Weaver JA, Bordelon CB, Randerath K. ${ }^{32} \mathrm{P}$-postlabeling analysis of DNA adducts persisting for up to 42 weeks in the skin, epidermis and dermis of mice treated topically with 7,12-dimethylbenz[a]anthracene. Carcinogenesis 1985;6: 111726.

31. Reddy MV, Randerath K. Nuclease P1-mediated enhancement of sensitivity of ${ }^{32}$ Ppostlabelling test for structurally diverse DNA adducts, Carcinogenesis 1986;7:1543-51.

32. Reddy MV, Bleicher WT, Blackburn GR, Mackerer ER. DNA adduc- 
tion by phenol, hydroquinone, or benzoquinone in vitro but not in vivo: nuclease P1-enhanced 32P-postlabeling of adducts as labeled nucleoside bisphosphates, dinucleotides and nucleoside monophosphates. Carcinogenesis 1990;8:1349-57.

33. Stiborová M, Sejbal J, Bořek-Dohalská L, Poljaková J, Forsterová K, Rupertová M, Wiesner J, Hudeček J, Wiessler M, Frei E. The anticancer drug ellipticine forms covalent DNA adducts, mediated by human cytochromes $\mathrm{P} 450$, through metabolism to 13-hydroxyellipticine and ellipticine $\mathrm{N}^{2}$-oxide. Cancer Res 2004;64:8374-80.

34. Stiborová $M$, Poljaková J, Ryšlavá H, Dračíinský M, Eckschlager T, Frei E. Mammalian peroxidases activate anticancer drug ellipticine to intermediates forming deoxyguanosine adducts in DNA identical to those found in vivo and generated from 12-hydroxyellipticine and 13-hydroxyellipticine. Int J Cancer 2007;120:243-51.
35. Gupta RC, Earley K. ${ }^{32} \mathrm{P}$-adduct assay: comparative recoveries of structurally diverse DNA adducts in the various enhancement procedures. Carcinogenesis 1988;9:1687-93.

36. Stiborová $M$, Mikšanová $M$, Šulc $M$, Rýdlová $H$, Schmeiser HH, Frei E. Identification of a genotoxic mechanism for the carcinogenicity of the environmental pollutant and suspected human carcinogen o-anisidine. Int J Cancer 2005;116:667-78.

37. Stiborová $M$, Mikšanová $M$, Smrček $S$, Bieler CA, Breuer A, Klokow $\mathrm{KA}$, Schmeiser HH, Frei E. Identification of a genotoxic mechanism for 2-nitroanisole carcinogenicity and of its carcinogenic potential for humans. Carcinogenesis 2004;25:833-40.

38. Huska D, Adam V, Babula P, Hrabeta J, Stiborová M, Eckschlager T, Trnkova L, Kizek R. Square wave voltametry as a tool for investigation of doxorubicin interactions with DNA isolated from neuroblastoma cells. Electroanalysis 2009;21:487-95. 